OPEN ACCESS

Edited by:

Wen-Cheng Wang,

National Taiwan Normal University,

Taiwan

Reviewed by:

Michael Fabinyi,

University of Technology Sydney,

Australia

Edward Jeremy Hind-Ozan, Cardiff University, United Kingdom

*Correspondence:

Janne R. Rohe

janne.rohe@leibniz-zmt.de

Specialty section: This article was submitted to

Marine Conservation and

Sustainability,

a section of the journal

Frontiers in Marine Science

Received: 07 November 2016 Accepted: 18 May 2017 Published: 31 May 2017

Citation:

Rohe JR, Aswani S, Schlüter A and Ferse SCA (2017) Multiple Drivers of Local (Non-) Compliance in Community-Based Marine Resource Management: Case Studies from the South Pacific. Front. Mar. Sci. 4:172.

doi: 10.3389/fmars.2017.00172

\section{Multiple Drivers of Local (Non-) Compliance in Community-Based Marine Resource Management: Case Studies from the South Pacific}

\author{
Janne R. Rohe ${ }^{1,2 *}$, Shankar Aswani ${ }^{3}$, Achim Schlüter ${ }^{1,2}$ and Sebastian C. A. Ferse ${ }^{4}$ \\ ${ }^{1}$ Department of Social Sciences, Leibniz Centre for Tropical Marine Research, Bremen, Germany, ${ }^{2}$ Department of \\ Economics, Jacobs University, Bremen, Germany, ${ }^{3}$ Departments of Anthropology and Ichthyology and Fisheries Science, \\ Rhodes University, Grahamstown, South Africa, ${ }^{4}$ Department of Ecology, Leibniz Centre for Tropical Marine Research, \\ Bremen, Germany
}

The outcomes of marine conservation and related management interventions depend to a large extent on people's compliance with these rule systems. In the South Pacific, community-based marine resource management (CBMRM) has gained wide recognition as a strategy for the sustainable management of marine resources. In current practice, CBMRM initiatives often build upon customary forms of marine governance, integrating scientific advice and management principles in collaboration with external partners. However, diverse socio-economic developments as well as limited legal mandates can challenge these approaches. Compliance with and effective (legally-backed) enforcement of local management strategies constitute a growing challenge for communities - often resulting in considerable impact on the success or failure of CBMRM. Marine management arrangements are highly dynamic over time, and similarly compliance with rule systems tends to change depending on context. Understanding the factors contributing to (non-) compliance in a given setting is key to the design and function of adaptive management approaches. Yet, few empirical studies have looked in depth into the dynamics around local (non-) compliance with local marine tenure rules under the transforming management arrangements. Using two case studies from Solomon Islands and Fiji, we investigate what drives local (non-) compliance with CBMRM and what hinders or supports its effective enforcement. The case studies reveal that non-compliance is mainly driven by: (1) diminishing perceived legitimacy of local rules and rule-makers; (2) increased incentives to break rules due to market access and/ or lack of alternative income; and (3) relatively weak enforcement of local rules (i.e., low perceptions of risk from sanctions for rule-breaking). These drivers do not stand alone but can act together and add up to impair effective management. We further analyze how enforcement of CBMRM is challenged through a range of institutional; socio-cultural and technical/financial constraints, which are in parts a result 
of the dynamism and ongoing transformations of management arrangements. Our study underlines the importance of better understanding and contextualizing marine resource management processes under dynamic conditions for an improved understanding of compliance in a particular setting.

Keywords: community-based marine resource management (CBMRM), compliance, enforcement, legitimacy, customary governance, transforming management, South Pacific

\section{INTRODUCTION}

The effect of formal and informal rule systems to manage natural resources largely depends on people's compliance behavior (Keane et al., 2008). In other words, rule compliance fundamentally influences the outcomes of conservation and related management interventions. In the marine realm, compliance has been linked to the ecological performance of marine protected areas (Pollnac et al., 2010; Campbell et al., 2012). In a broader sense, non-compliance with environmental regulations can threaten social and economic management objectives (Arias et al., 2015). Therefore, understanding drivers of (non-) compliance is crucial for the design and implementation of marine management efforts.

Compliance can generally be defined as people's behavior that conforms to formal or informal rules which have emerged to influence actions (Tyler, 2006; Hauck, 2008). Within the fisheries context, the literature has highlighted different theoretical and empirical dimensions of compliance (Sutinen and Andersen, 1985; Kuperan and Sutinen, 1998; Hønneland, 1999; Sutinen and Kuperan, 1999; Hauck, 2008; Arias, 2015). Economic analyses of fisheries compliance have stressed that an individual's decision to comply or not with a rule is mainly based on a consideration of the potential economic costs (related to the certainty and severity of sanctions) and benefits of doing so (Sutinen and Andersen, 1985; Hatcher et al., 2000). More norm-based perspectives on compliance have emphasized internal and social incentives for (non-) compliance such as normative values, morality, perceptions of legitimacy and social justice (Hønneland, 1999; Jentoft, 2000; Raakjaer Nielsen, 2003; Hauck, 2008).

The influence of the perceived legitimacy of rules on the rule acceptance by resource users has been widely stressed (Sutinen and Kuperan, 1999; Jentoft, 2000; Keane et al., 2008). Legitimacy aptly refers to the acceptance of decision-making and its outcomes by citizens (Van Tatenhove, 2013). It is related to the "perception that the actions and products of a certain entity are wished for and in accordance with a socially constructed set of norms, values, principles and definitions" (Van Tatenhove, 2011, p. 91). If resource users do perceive the rules and decisionmaking as legitimate, it is more likely that they choose to comply (De Vos and Van Tatenhove, 2011). The two perspectives, the more normative, i.e., norm-based, and the economic/rational choice view, on compliance are not mutually exclusive (Schlüter and Theesfeld, 2010). Furthermore, compliance is dynamic, changing in response to the local context. Thus, elements of both perspectives, as well as an analysis of how rules developed and what influenced them, are needed to gain a better understanding of compliance dynamics. Such analysis should therefore also question who defines rules and (non-) compliance as well as the power dynamics inherent in these processes (Hauck, 2008).

Moreover, monitoring and enforcement is considered a key part of successful natural resource management (Ostrom, 1990; Gezelius, 2002; Keane et al., 2008) that can contribute to improved compliance behavior. It is often argued that the effectiveness of monitoring and enforcement influences how people evaluate the risks of rule-breaking (certainty and severity of sanctions) and thus determines the deterrent threat-which can influence people's consideration whether breaking a rule is worth the risk (Jackson et al., 2012).

Marine governance and natural resource management systems are contextual, dynamic and continuously adapting to transforming social, political, economic and ecological conditions (Ostrom, 2007; Aswani and Ruddle, 2013). We argue that a better understanding of compliance dynamics, analyzing under what pressures and circumstances compliance can decrease or increase, is useful to gain improved insights into overall governance dynamics. This can be crucial to inform adaptive management of marine resources.

In this article we conduct a study of two cases, located in Fiji and Solomon Islands, for an in-depth analysis of local compliance with local marine resource management. In both Melanesian countries inhabitants have long records of interaction with the marine environment. Customary tenure systems have been the prevailing management regime for inshore fisheries in the South Pacific for a long time (Johannes, 2002; Caillaud et al., 2004; Govan et al., 2009). However, these systems have not been static over time. In the late twentieth century customary marine tenure approaches seemed to be eroding due to various impacts of "westernization," e.g., the introduction of top-down management approaches and new fishing techniques as well as evolving market dynamics (Johannes, 1978). For the past two decades though, a reinvigoration of these initiatives has been ongoing, based upon communities' traditional knowledge and customary rights whilst integrating modern management principles and scientific advice (Johannes, 2002; Cinner and Aswani, 2007). Hence, in current practice, a hybrid that combines customary tenure systems and science-based conservation approaches is often promoted (Aswani and Ruddle, 2013).

In many cases this happens in collaboration with nongovernmental organizations (NGOs) and other partner organizations, including from government, which brings in new actors and influences local management practices (Cohen and Steenbergen, 2015). These community-based management approaches have received wide recognition given their potential to promote local food security, sustainable fisheries management, and marine conservation (Govan, 2013; Weeks and Jupiter, 
2013). Yet, customary governance and institutions-which are still at the core of these approaches-are being challenged by diverse socio-economic developments as well as cultural changes. This results in transformations, which have long been a feature of the Oceanic region (Aswani and Ruddle, 2013). Additionally, local leaders are constrained in their capacity to enforce local marine tenure rules owing to limited legal mandates. This is due to the fact that these rules, many of which are area-based (e.g., in the form of marine closures), are generally not legally gazetted under national law. In this study we will look at such marine closures, which we refer to as "managed areas."

This study examines the emergent conditions that may challenge compliance with CBMRM-which can ultimately hinder it from achieving the above-mentioned social and ecological aims. We ask two questions: (1) what socio-cultural, economic and legal conditions drive local (non-) compliance within CBMRM? And (2) what challenges, and what supports, the effective enforcement of CBMRM? Previous studies in the region have examined local compliance with fishery rules and regulations (including national-legal; e.g., Pomeroy et al., 2015), where monitoring and enforcement mechanisms vary. Others (e.g., Jupiter et al., 2010) have examined compliance with CBMRM, including by "outsiders"-who do not have customary fishing rights to a given fishing ground. Overall, little attention has been given to a more in-depth assessment of compliance behavior of local villagers who have customary fishing rights within the respective managed area. Given locals' unique rights situation and the limited legal mandate for enforcing marine closures, it is important to elucidate different drivers of local (non-) compliance while scrutinizing the role of local social, political and economic contexts and their dynamism. This is the primary purpose of the present study.

\section{METHODS}

\section{Study Sites}

Research was conducted at one site in each of Solomon Islands and Fiji (from now on referred to as SI and FJ, respectively). The case study sites were selected purposively, which allowed choosing cases that illustrate features or processes considered relevant for this study (Silverman, 2010). Research sites were selected to feature communities that: (1) directly use local marine resources, (2) have some form of management regime established for a considerable period of time, and (3) where management arrangements have been supported and accompanied by partner agencies as part of conservation and development initiatives. These three factors were considered because they are likely to influence (perceptions of) management and compliance dynamics.

\section{Fiji}

In Fiji, the Fisheries Act (Cap. 158) grants native Fijians customary fishing rights in their respective traditional fishing ground (qoliqoli) (Minter, 2008). Customary chiefs and clan heads can control access to fishing areas and make decisions regarding local marine tenure. Generally, chiefs and communities have decisive authority over local resource management
(Veitayaki, 1998). Fishing areas are clearly demarcated and thus spatially define access rights (Weeks and Jupiter, 2013). Although the Fisheries Act remains the primary piece of legislation for inshore fisheries, customary right holders have unique and exclusive access rights to their traditional fishing ground. This creates a legal pluralist situation that can challenge local enforcement capacities in the face of current CBMRM practice.

In Fiji a village on the island of Ovalau, Lomaiviti Province, served as local case study site (FJ, Figure 1). With its $\sim 350$ inhabitants, FJ shares a traditional fishing ground with four other villages, although these have separate managed areas. In this village, marine resources and fishing have traditionally been an important part of peoples' lives. Yet, other livelihoods (mainly small-scale agriculture) are available and additional income-generating activities (mainly through employment in the nearby fish factory, especially for women) are practiced. The village set up a managed area in the form of a periodicallyharvested closure in front of the village about 10 years ago, with assistance of a regional network and other partners. The site has generally remained closed to any harvesting activities since its establishment. However, a small section of the managed area has been opened several times for a couple of days in cases of chiefly (or other important villagers') deaths.

\section{Solomon Islands}

In Solomon Islands the constitution and fisheries legislation also recognize customary rights. Diverse socio-cultural, historic and economic processes have created differential and contested territorial customary rights systems. As a result, customary marine tenure systems vary regionally and are generally more stratified, decentralized and politically eclectic than in Fiji (Aswani, 1997, 1999).

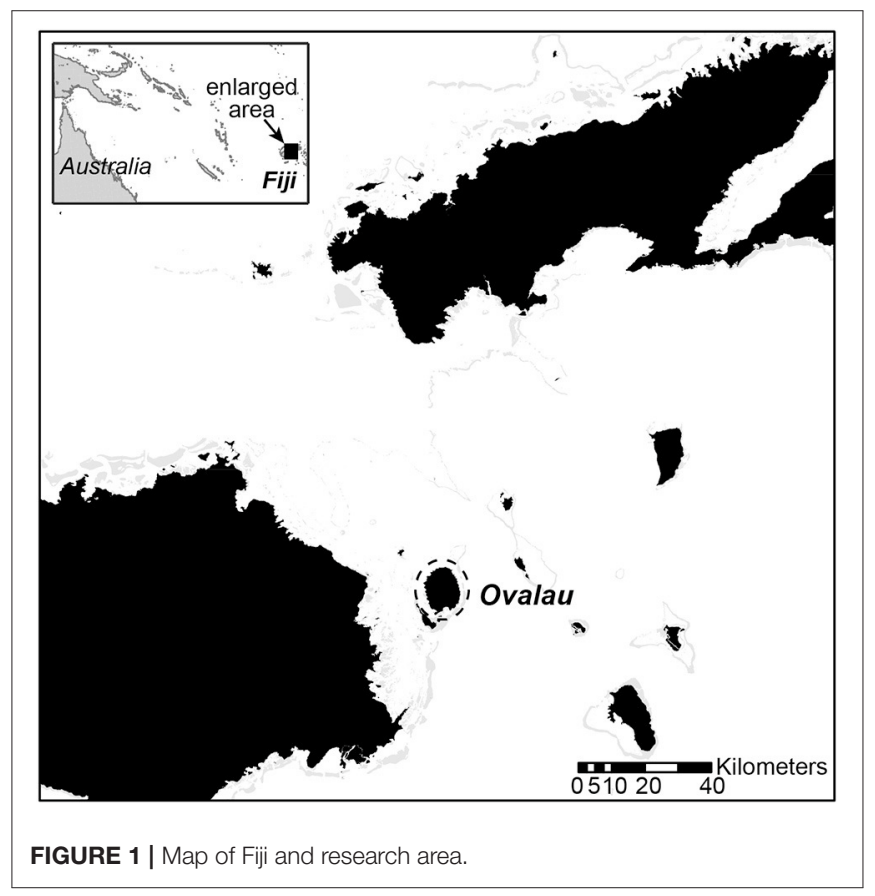


In Solomon Islands, our research was conducted in a village in Roviana Lagoon in the Western Province (SI, Figure 2). In this area, customary chiefs and elders control access to and use of marine resources. Villages in Roviana Lagoon are remote and only accessible by boat. Approximately 1,000 people live in SI. Households are highly dependent on marine resources. Fishing is the single or second most important livelihood, together with small-scale agriculture. Local marine resource management consists of a marine closure in front of the village that is permanently closed for all fishing and other marine harvesting activities. This site forms part of a marine conservation and development program initiated in the late 1990s that included 32 management sites across the Western Solomon Islands. The program was established with advice of foreign academic experts and was financially supported through external (international) donors (see Aswani et al., 2007). A community-based organization (CBO), founded in the course of the program, assisted with the management and implementation of the marine closure in collaboration with local leadership (customary and church leaders) and a local resource management committee that was created for this purpose.

\section{Qualitative Data Collection}

In this study we wanted to examine the complexities of locals' perceptions and behavior around compliance, while considering the local cultural context, including the meaning of norms and informal rules. Ethnographic data were collected using various qualitative methods (Corbin and Strauss, 2008; Silverman, 2010). We employed semi-structured and key-informant interviews (total $n=63$; thereof 29 in Fiji and 34 in Solomon Islands), focus group discussions (total $n=5$; thereof 3 in FJ and 2 in SI) and participant observations. Policy and legal documents (fisheries legislation) served as secondary data sources for triangulation.

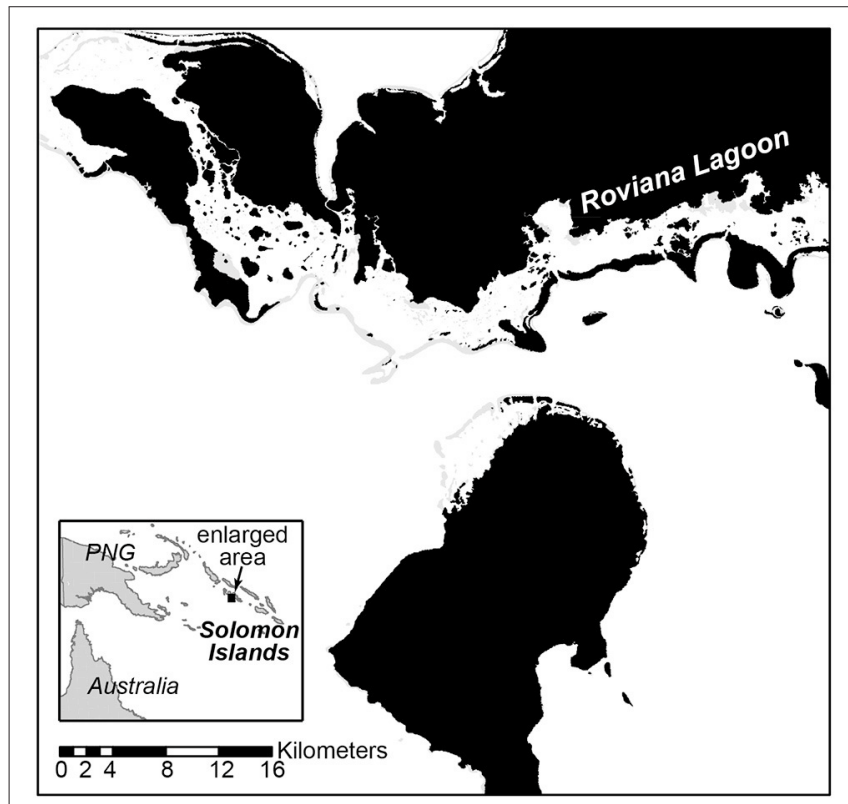

FIGURE 2 | Map of Solomon Islands (Western Province) and research area.
Data were collected over a 2 month period in each country, between April and June 2015 in Solomon Islands and between August and September 2015 in Fiji.

A total of 99 persons participated in the study, 48 of which participated in Solomon Islands and 51 in Fiji. Interviews and focus groups involved respondents from different governance levels: village $(n=76)$, province $(n=4)$ and national $(n=19)$. At the national and provincial levels interviews were conducted in English. Interviews and focus groups with village respondents were held in the respective local language (Fijian and Roviana), with the help of local interpreters. Prior informed consent was sought orally from all research participants. Research was conducted in accordance with all ethical standards outlined in the White Paper on Safeguarding Good Scientific Practice by the German Research Foundation (DFG, 2013). An ethics approval was not required according to the DFG guidelines, as well as to our institutional guidelines and the regulations in the study locations. All required procedures for conducting research and obtaining research permits in the study locations were followed closely.

\section{Sampling}

At the village level, interviewees were selected purposively to cover a broad range of potentially relevant respondent characteristics and individual perceptions. The following contextual variables were developed for this sampling process: (1) marine resource users; (2) persons involved in local decisionmaking; (3) age; (4) gender; (5) church denomination (mainly for the Solomon Islands case study, where this emerged as a key aspect for people's role within and perceptions of the community); (6) involvement in other livelihoods apart from fishing (mainly for the Fijian case study, where this seemed to lower direct resource dependency and hence influence views on the marine closure and compliance issues). Interviews were used to get an overview of relevant themes and divergent views regarding local (non-) compliance. Selecting interviewees at the village level was done in an iterative process. Thus, initial analysis and results gained through the interviews were used to elaborate the above-mentioned contextual variables and to select further interviewees as well as key informants. Interviews at the village level were conducted until no new additional information or themes were emerging (i.e., until saturation was reached).

Interviewees may not represent the view of everyone in the village due to the fact that we used non-random sampling. In order to minimize potential biases (e.g., due to personal networks and social relations) during the selection of research participants, we worked with interpreters who were not from the research sites.

Focus groups built upon key themes that emerged from the interviews, allowing for data triangulation. Focus groups were comprised of seven to eight participants each. They were conducted separately for women, men, and in Fiji also for the youth, because there a stronger generational differentiation became apparent. The majority of the focus group discussants were involved in fishing. Some (especially older men) were or had also been involved in local decision-making, and some had a different income source (especially women in the Fijian case study through employment in the fish factory). Focus 
group participants were chosen purposefully in collaboration with local field assistants while seeking a good balance of potentially relevant characteristics of the participants (e.g., church denomination in the Solomon Islands case study).

At the provincial and national levels, representatives from relevant ministries or departments (e.g., fisheries and environment), civil society (e.g., NGOs and international organizations) and academia were interviewed. Purposive and snowball sampling was used to identify respondents at these levels. Using a snowball sampling approach runs the risk that only certain opinions are heard due to path dependencies. In order to avoid this fallacy we sought specifically to interview actors with potentially opposing views.

\section{Interview Guidelines and Questioning}

For data collection at the village level we used indirect questioning, i.e., asking respondents about the compliance behavior of others and not (necessarily) their own. This was done in order to diminish potential response biases (people giving inaccurate information), as well as nonresponse biases (people refusing to give information) (Arias et al., 2015). Such biases were expected because questions around (non-) compliance touch upon sensitive issues, especially in a small village setting. The utility of such an assessment of what can be referred to as "perceived compliance" as a proxy for actual compliance has been demonstrated in other studies (Arias and Sutton, 2013). Yet, it should be taken into account that theories such as the social norms approach (Berkowitz, 2005) argue that people tend to overestimate the non-compliant and negative attitude of their peers beyond their actual behaviors. Nevertheless, it is also conceivable that a direct approach would not have revealed much non-compliance either, or that interviewees would have belittled their own infringements.

Guidelines were used for the interviews and focus groups at the village level (see Supplementary Material). Through the interviews we first wanted to gain an understanding of the local marine resource management arrangements, changes regarding these arrangements, and peoples' perceptions of them. Therefore, interview questions firstly enquired about: existing and previous local marine resource management, perceptions of their purpose and benefits, issues regarding local decision-making, and peoples' participation in it. Secondly, questions were asked about: perceptions of local compliance with rules, enforcement, and local management of disputes. Similar questions and themes to the ones addressed in the interviews guided the focus groups, though in a more interactive and collective way (Mancini Billson, 2006). For example, participants were asked to discuss reasons for non-compliance and collectively identify and rank the most important drivers of non-compliant behavior, while being asked to explain for whom (which group) these drivers were important and why. Furthermore, participant observations (e.g., attending informal gatherings, a village market, and a church service; going to sea with fishers; accompanying locals on village walks) were used to further contextualize and triangulate information obtained otherwise.

At the provincial and national levels interviews enquired about: respondents' perceptions of the potentials and challenges of local marine resource management in their country, their views on local compliance, enforcement, and the role of the national legislation (and, if applicable, of the respondents' agency) with regards to this.

\section{Data Analysis}

Data from all interviews and focus groups were transcribed and analyzed inductively through open, axial and selective coding (Corbin and Strauss, 2008). Qualitative data analysis software (MAXQDA) was used to identify and relate emerging themes and patterns from the transcripts and to link these to secondary data sources (e.g., legislations) as well as to the theoretical and empirical literature. Further information on the codes used for the analysis can be found in the Supplementary Material.

\section{RESULTS}

Data from our research reveal that in both study sites many locals-including some who were non-compliant-perceived local non-compliance with the marine closure as a problem with the potential to dismantle the social and ecological effects of these local management efforts. In SI, consensus was reached in the focus group discussions that people from different age groups, gender, and church denominations were inclined to disobey the managed area. In FJ, our data from interviews and focus groups reveal that mainly young male divers who lacked an alternative stable income tended to disobey the marine closure. In FJ, due to its relative closeness to the capital city, the managed area was challenged by external poachers (mostly commercial fishermen with fast boats) besides local non-compliance.

In the following, we summarize the main aspects related to (non-) compliance that emerged from our two cases, before presenting individual results from each case study.

In both case studies, results from the interviews and focus group discussions suggest that lowered perceived legitimacy of local rules (including the marine closures) and leadership was acting as a driver of non-compliance with the local marine resource management. Furthermore, economic incentives, e.g., related to market opportunities to sell fish, influenced noncompliance, too. Additionally, we find that the physicalgeographical conditions of the managed areas, mainly related to their size and location, constrained villagers in accessing their primary fishing grounds, and thus promoted non-compliant behavior. Finally, our study reveals different barriers for monitoring and enforcement in the context of the two case studies. In both countries (and both case study sites), managed areas were generally not legally gazetted, and thus enforceable, under national law. This means monitoring and enforcement of local marine management in FJ and SI relied on local villagers and customary governance systems. Yet, in both case study sites these were constrained in a number of ways.

\section{Fiji}

\section{Lowered Legitimacy of Rules and Rule-Makers}

In FJ our study reveals two sets of aspects that partly constrained perceived legitimacy of the managed area, particularly for young fishermen. Firstly, data from interviews and focus groups reveal that a lack of participation and consultation regarding the local management, particularly about the size and location of the 
managed area, lowered perceptions of its legitimacy. Especially male youth, but partly also older women, voiced that they did not feel involved or consulted during the establishing process of the managed area-and thus perceived the managed area as illegitimately constraining their customary fishing rights. In Fiji, the Fisheries Act grants customary rights to fish inside a certain qoliqoli (traditional fishing ground) to every native Fijian whose mataqali (clan or other subdivision) has been registered by the Native Fisheries Commission. This basically applied to all inhabitants of FJ. Although older male informants expressed, and other sources confirmed, that a consultation process did take place, it might not have involved all actors within the village that currently impacted upon and were impacted by the managed area. The current youth were still too young to witness the establishment process of the managed area 10 years ago, and were hence not part of that consultation. Women did not participate actively during workshops for other reasons (e.g., due to traditional gender roles that constrain women from actively participating in such meetings, or time constraints related to family responsibilities, or work at the fish factory).

Secondly, the current managed area varied from customary tenure arrangements practiced in earlier times with regards to its permanent nature as well as to its (perceived) main purpose. The first aspect relates to a change in the periods of closures. Data from our study reveal that the managed area was set up in a way that locals perceived as a permanent closure. Although customary leadership decided a few times to open one section of the managed area in the past in case of a chief's or another important villager's death, the "general status" of this part of the fishing ground was "closed." In previous times, the general status was "open," with temporal closures of a smaller section of the fishing ground to commemorate when a chief died. Therefore, villagers generally perceived the current managed area as permanent closure. This means the managed area was restricting fishing activities considerably more than previous practices used to. The second aspect relates to the perceived main purpose of the management interventions. Previously, customary approaches had served to impose periodic closures for special cultural and social events (commemoration of a chief's death). Indicated by consensus reached in a focus group discussion, these customary closures were thus perceived as mainly serving the (socio-cultural) purpose of having food for that special occasion and not for resource management. Focus group discussions disclosed that in current practice, locals perceived the aim of the managed area as being more focused on (longer-term) conservation objectives (notwithstanding that these conservation objectives are ostensibly linked to ensuring food security and thus allow for a continuation of the culture of fishing).

Both factors, the lack of participation and consultation as well as perceptions of the altered nature and purpose of the management arrangement, were especially stressed by young fishermen. Among this constituency, they lowered feelings of ownership for the local management initiative and increased the perception that the restriction of their customary fishing rights by the managed area was illegitimate. This in turn then drove non-compliant behavior by this group.

\section{Market and Income Opportunities as Incentives}

There was consensus among respondents that in FJ especially young men resorted to poaching as (small-scale) income generating activity. They mainly did so when they did not have an alternative source of income, such as work in the near-by fish factory. Because the catch per unit effort (CPUE) was (perceived) higher inside the managed area, fishing there promised a fast catch and easy cash when selling the fish, which happened mainly on local markets.

\section{Physical-Geographical Conditions of Marine Closures}

In FJ the managed area was located right in front of the village, stretching from the shore to the outer reef slope. This area had been chosen because indigenous ecological knowledge indicated that it was especially ecologically relevant. Yet, its location clearly limited the accessibility of the (permitted) fishing grounds. It implied that local fishers either had to walk long distances during low tide or that they needed a boat-which were rare. There was only one bamboo raft and two fiberglass boats available in the village; the latter came with costs for the fuel. These limitations to access the fishing grounds outside the managed area, implying more time and money investments, were an impediment to compliance with the managed area. Respondents throughout the interviews agreed that this could further promote fishing inside the managed area. This was more likely when coupled with the above-mentioned economic incentives, and applied especially to young fishermen who lacked an alternative livelihood or income.

\section{Barriers for Monitoring and Enforcement}

Although most managed areas are not legally gazetted in Fiji, they do receive partial legal back-up under the Fisheries Act under two scenarios. Communities can "arrest" a poacher who is caught fishing inside the managed area and take this person to the police or closest fisheries office if: (1) it is a licensed fisher who is not respecting the managed area (more commonly applies to commercial fishers from outside the village who do not have customary fishing rights in this area), because license conditions prescribe that local (customary) management rules ought to be respected, or (2) someone is selling fish (no matter where the fish was caught) without having a license. Nonetheless, these scenarios have limited applicability to local non-compliance where people draw on customary fishing rights to engage in subsistence fishing. Under the current Fisheries Act small-scale sale of catch that exceeds subsistence needs has so far been tolerated for customary fishing right holders. This is why the second scenario does usually not apply to local poachers. Yet, this issue has been recognized as a gray area and will probably be addressed in the course of reviewing the fisheries legislation-a process that was initiated in 2006 and is still ongoing.

\section{Institutional Constraints}

In $\mathrm{FJ}$ it is common to announce local poachers in village meetings or during church services. Commonly the chief or village headman speaks to that person to issue an oral warning, too. Nevertheless, respondents agreed that the deterrent threat of these penalties was not very high, especially because there were no graduated sanctions (nothing more serious happens 
if that person poaches again). Further enforcement efforts of local marine resource management initiatives remained limited. In order to enforce managed areas under national law-in Fiji under one of the two scenarios described above-the police or another state authority would need to get involved. In Fiji local voluntary fish wardens are appointed to monitor local marine tenure rules (managed areas). At the same time these wardens are tasked with monitoring local compliance with national regulations, such as species restrictions and mesh size of nets, under the Fisheries Act. Fish wardens can be appointed by the Minister of Fisheries after receiving training by the Department of Fisheries. They are not paid nor do they receive any substantial financial support or equipment. Not all villages in Fiji have fish wardens-it rather depends on the initiative of the village itself and/or supporting partner organizations. Fish wardens or local leadership who want to report infringers to the police need to keep and demonstrate evidence of the infringement (e.g., confiscated catch, gear, boat). Yet, besides the training that fish wardens receive by the Department of Fisheries, they are not trained as prosecutors, and thus not familiar with the details of keeping evidence. Additionally, fish wardens often face police officers who are not aware of the fisheries legislation or who are reluctant to investigate and prosecute fisheries crimes.

Furthermore, findings from FJ show that, in former times, the temporal closures on fishing areas declared by customary leaders were more strongly related to a socio-cultural purpose and tradition (chiefly deaths). As a result, these taboos were more respected than current managed areas because "it [was] part of tradition and [breaching it] would go directly against the chief," as expressed by one respondent in FJ. The current managed area had been supported by partner organizations that have more clearly brought in conservation objectives as part of a sustainability discourse. Consequently, locals perceived the managed area in FJ less as a strict taboo in the traditional sense. Thus, offenses were perceived to oppose rules that had been influenced by external actors, instead of directly opposing a chiefly decision.

\section{Socio-Cultural Constraints}

Our study reveals various socio-cultural constraints for local monitoring and enforcement in FJ. Firstly, fish wardens were constrained in reporting local infringers due to the strong network of clan and family relationships they were embedded in. This means fish wardens usually knew local infringers well and might therefore have been reluctant to report non-compliant behaviors, as this might have negatively impacted their own social relations. The same limitation applies to chiefs and clan heads, who would decide about consequences to take against local poachers if these were reported by the fish wardens or other community members.

Secondly, the selection process for appointing fish wardens did not seem to be transparent and not everyone within the village was aware of the identity and the role of the wardens. This further impeded their work because some people might not have recognized their authority at all, or (again), perceived it as less legitimate.

\section{Technical and Financial Constraints}

In FJ villagers agreed that the area of the marine closure was too big to monitor from the shore, and monitoring would thus require patrols by boat. Yet, boats and/or money for fuel for the boats were lacking. Detection of infringers was further made difficult because poaching occurred at night most of the times. Additionally, respondents throughout interviews agreed that two fish wardens for the managed area were not sufficient, especially given that both of them were active fishermen, too. This means that many times they were involved in harvesting activities themselves while not being able to solely concentrate on monitoring the managed area.

\section{Solomon Islands}

\section{Lowered Legitimacy of Rules and Rule-Makers}

In SI data from our study disclose that two developments generally lowered the perceived legitimacy of local leadership, which included chiefs and the council of elders who made decisions about marine tenure, persons who implemented these (e.g., rangers), and the church. One of these developments was associated with the (perceived) misuse of money; firstly in relation to logging activities that were ongoing on the main island opposite the village, but also with regards to the management of the managed area. Since inhabitants of the community owned the land where the logging company was operating, they had been receiving a substantial amount of "royalty payments" on a regular basis. This money was given to some of the leaders ("trustees") to share it among the community. A large proportion of interviewed villagers perceived that this did not happen in a transparent and equal way. This caused perceptions of unequal benefits and procedural unfairness in SI, and was given as a reason for non-compliant behavior as a payback strategy against the leaders.

Similarly, many locals perceived that the money that was given by international donors to support the local $\mathrm{CBO}$ and resource management committee (including local rangers) was not being used transparently and in a way that was beneficial to everyone. Particularly some women expressed their growing mistrust toward the (predominantly male) leadership, highlighting that they no longer followed rules (i.e., the managed area) made by this leadership. As one woman pointed out when asked about conflicts with regards to the managed area: "Yes, there were also conflicts, especially with the money. These people [referring to the local leadership] are not reliable. [...] They are not transparent. [I] was one of these poachers [...]. [But] I was not poaching, [I] was showing that [I] was not happy about the decisions [the leadership was taking], so when they [rangers] came up, [I] would tell them 'you tell me where the money went, and then I stop fishing in this area." In SI women actively participated in fishing and harvesting of other marine resources (mainly shells), thus providing an important food source for their families. Yet, they hardly took part in local decision-making processes, including with regards to the management of marine resources, and were underrepresented in leadership committees such as the council of elders. Over the last century chiefs were mostly male, too. 
The second development that led to diminished, and divergent, perceptions of the legitimacy of the council of elders and leadership in SI was related to the division of the predominant local church. In SI religious leaders played an important role within customary governance processes for a long time and were involved in ongoing conservation and management initiatives. The leader of the predominant local church gave his blessing for the managed area years back (in 2005), which was of great importance and meaning for locals in order to respect it as conservation area. Later, when this spiritual leader fell sick, discussions about his succession turned into a conflict between the two competing aspirants and their respective supporters. The church members were divided into two groups. The division affected the council of elders and other leadership meetings, too, because most of their members belonged to one or the other group. Since the death of the (former) spiritual leader in 2014, animosities between both groups increased further. The schism not only generated divergent views as to which spiritual leader to follow from now on, but also doubts about the acceptability of leadership, such as the council of elders, and their decisions. Data from interviews and focus groups reveal that it also generally deteriorated feelings of shared group membership and identity as well as trust within the community. This further diminished cooperative and prosocial behaviorincluding with regards to the managed area, where this led to more non-compliance.

A further aspect that is enhancing heterogeneity of the local population and adding to socio-cultural diversity is the fact that in SI, many people from other tribes and provinces were marrying into or out of the village. This was referred to as "intermarriage" and was a common theme coming up throughout interviews with diverse respondents. Although intermarriage does not necessarily lead to disunity, it was mostly raised as potential problem that had detrimental effects including on compliance with the managed area. An older fisherman in SI expressed: "[...] Those people who are married here, because they have different traditions and "kastoms" in their respective homes, they just don't tend to follow [the rules set by the local leaders, such as the managed area]."

Our study shows that people's decisions to comply were influenced by the perceived compliance behavior of others in the community and perceived unequal distribution of benefits (from rule-breaking), as this statement by a male respondent in SI underlines: "I support not to fish in conservation areas. But if I keep on talk talk talk to members of the community not to go out [to fish inside the managed area], and people do not listen to me, do you think I will keep on talking talking talking? I will also want to have fish. In turn I will go and fish [inside the managed area], too."

Finally, and similarly to findings from FJ, results from a focus group in SI reveal that locals perceived the current marine closure as an alteration of former customary practices and temporal closures. This was firstly due to its permanency, and secondly, due to a perceived shift from a socio-cultural purpose toward a stronger focus on conservation objectives.

\section{Market and Income Opportunities as Incentives}

In SI there was consensus throughout the focus group discussions that poaching within the managed area for an income intensified when new market access opportunities arosethrough middlemen and ships of the logging company operating nearby. The latter offered access to the market of the island's capital because villagers could put their coolers with fish for free on the logging ships when they made their way to the capital harbor, and sell it there. In SI alternative sources of cash income apart from fishing for sale were limited to marketing of local products, including copra, and operating small stores. Hence, for people wishing to earn some money (e.g., to pay school fees for their children or for church contributions) instead of living merely on a subsistence basis, poaching and selling the fish became more attractive. Again, there was consensus among respondents that the CPUE inside the managed area was higher (which is also related to the biophysical and ecological characteristics of that area), which further incentivized fishing inside the area for an "easy catch."

\section{Physical-Geographical Conditions of Marine Closures}

In SI the managed area was located directly in front of the village, too. The location of the marine closure had been decided based upon: indigenous ecological knowledge, scientific ecological surveys, and ease of monitoring (due to its proximity to the village), and the decision happened in consultation with the local leadership. Interview respondents similarly agreed that some (in this case especially older) people poached because they were "too tired to go far out to fish." Further, female respondents raised the complaint that the closure particularly constrained their fishing activities because it was set up in an area where mainly women used to fish. As one (female) respondent put it: "That is the number one place where [women] used to fish!" She further explained, and other respondents confirmed, that this was due to the area's closeness to the village. Women, due to their multiple responsibilities in the household and involvement with child care, could not afford to spend long hours fishing or go to more distant fishing grounds.

\section{Institutional Constraints for Monitoring and Enforcement}

In SI an interview respondent expressed that, apart from national laws that prohibited most customary penalties, the influence of missionaries and Christian imperatives weakened the effect of customary sanctions. This is related to the concept of "forgiveness" that was introduced by Christian missionaries in the early twentieth century. An old fisherman in SI explained: "Before missionaries came and before the church was here, our traditional governance [was] much more feared [...]. Because we only had one rule with[in] our traditions: you do something wrong which is against our traditions, we will kill you. [In the course of Christianization these penalty systems were weakened]: so when you break rule in our traditional way, the church comes in. That is forgiveness. When the church comes in, there is no longer value for our traditions." On the other hand, the involvement of the religious leaders in the marine conservation program in SI also served as a vehicle for reviving traditional 
systems and strengthened traditional leadership. Before the schisms of the local predominant church the fear of the spirit of the spiritual authority was very strong. But as the strength of this leadership weakened, so did the fear of retribution.

In general, the perceived risk of sanctions for non-compliance with the managed area was very low in SI, and therewith the deterrence threat for rule-breaking. Previously, non-compliance with the managed area used to be addressed in village meetings and/or church gatherings to publicly announce and warn offenders. This became less common since the schism and the resulting division of the community, because generally less village and leadership meetings took place since then. Also, the effect of verbal warnings and public announcement recently decreased due to the community division and resulting divergent views on the legitimacy of leadership which made these announcements.

\section{Socio-Cultural Constraints}

In SI the church schism and related division of the community also affected monitoring activities of the local rangers who used to detect and "arrest" (stop/talk to) local infringers who fished inside the managed area. Back then, incidents were reported to the local resource management committee and/or to the council of elders who would then announce it in respective meetings. When data for this study were collected, these rangers were no longer active and no one else took on the responsibility of monitoring. This was partly due to the mentioned socioreligious division of the community, as well as to other disputes around (the perceived misuse of) money and logging, which significantly weakened the role of the supporting $\mathrm{CBO}$ and the rangers.

\section{Technical and Financial Constraints}

In SI villagers and rangers had access to wooden canoes that can be used for monitoring the managed area. However, lack of funding for the $\mathrm{CBO}$ that was previously supporting the management and equipping rangers, e.g., with torches for their night shifts, is another reason, besides the ones mentioned above, that was recently constraining monitoring activities. Rangers had previously complained about a lack of regular salaries. A self-sufficient and sustainable structure to finance monitoring activities was envisaged by the supporting external partners in SI but did not succeed. Still, other (mainly female) interview respondents conveyed their impression that rangers were receiving payments for their work in the past, which in their eyes increased (financial) inequalities in the village.

\section{DISCUSSION}

Natural resource governance and management systems adapt to and are conditioned by the larger social, political and economic realms they are embedded in Aswani and Ruddle (2013). Compliance with these systems is equally dynamic. Recognizing this dynamism, and analyzing under what pressures and circumstances compliance can decrease or increase, can help to understand how to tackle problems in adaptive management of marine resources. In order to do so, we have taken a snapshot of (non-) compliance in two case studies in Melanesia.

Compliance has been recognized as fundamental for successful marine conservation (Keane et al., 2008; Arias et al., 2015; Cinner et al., 2016). Therefore, understanding drivers of (non-) compliance as well as barriers to enforcement is crucial in the assessment of marine management. In this study we find that people's compliance behavior is influenced by many factors. Non-compliance is partly driven by lowered perceived legitimacy of local decision-making and its outcomes. Furthermore, financial incentives and the physical-geographical conditions of the managed areas-constraining access to primary fishing grounds-can make fishing inside these areas more attractive or necessary. Finally, data from our study reveal that enforcement is impeded through various (institutional; socio-cultural; technical/financial) constraints, so that the deterrence threat for rule-breaking is rather low. These findings are consistent with other empirical studies and theoretical literature on compliance that have highlighted that both economic motivations as well as normative and social aspects-including around the process of how and by whom rules were set up-influence people's decision to comply (or not) (Gezelius, 2003; Hauck, 2008), and that monitoring and sanctioning is crucial, too (Ostrom, 1990; Gezelius, 2004; Keane et al., 2008).

These drivers and factors can act together and add up to impair effective management. For example, in FJ we find that young fishermen were more likely to poach when they did not have an alternative livelihood or other income. They did so more readily: firstly, because they felt that the managed area was illegitimately constraining their customary fishing rights (partly because they did not participate in its establishment process), and secondly, because they knew that potential penalties were unlikely (since they were making use of their customary fishing rights and did not have to fear sanctions under national law). In SI more people were poaching, and increasingly did so to make money as a consequence of easier market access, because perceptions of the legitimacy of leadership diminished as a result of the schism and perceived money misuse. Also, the community division resulting from the schism had weakened the role and endeavors (as well as acceptance thereof) of leadership and rangers with regards to monitoring and enforcing the managed area. Nonetheless, in SI the leader of the predominant local church had previously been a vehicle of the conservation initiatives, which first increased their perceived legitimacy amongst villagers. This again points to the dynamism of governance and local leadership, as well as their potential vulnerabilities. It is conceivable that a revitalization of this leadership will result in the re-establishment of the managed area and its rules and monitoring. This highlights the need to develop "fallback systems," especially when conservation initiatives build upon such local leadership structures.

\section{Contextualizing Drivers of Non-compliance}

In $\mathrm{FJ}$ the fact that current young fishermen were too young to witness the establishment process of the managed area, and 
thus did not participate or feel involved in decision-making for local marine resource management, turned into a driver for noncompliance for this particular group. Women were generally less involved in the consultation about the managed area, too. But because many women were employed in the fish factory, they did not perceive this as negatively as young fishermen, who depended more directly on fishing for their livelihood. Also, young local fishermen had witnessed commercial fishermen from the capital city poaching in the managed area. This might have further encouraged young local fishermen to fish inside the managed area because in the face of such a race for fish locals may have wondered why they should obey the marine closure if others were reaping the benefits. Other studies have similarly revealed that young age, which often goes along with less participation in the process of developing the rules, can lower support for and compliance with such rules (e.g., Schlüter and Madrigal, 2012; Madrigal-Ballestero et al., 2013). This highlights the importance of participation with equal access for and representation of all groups affected to generate legitimacy and increase rule acceptance (Jentoft, 2000; Van Tatenhove, 2013). In the cases studied here it was obviously not practically feasible to involve future fishing generations in the participation process 10 years ago. Yet, it shows that participatory, outreach and consultative processes should take place continuously and repeatedly to renegotiate management arrangements if necessary. In order to do so, funding programs that support partner organizations engaged in CBMRM would need to consider longer-term funding cycles and perspectives.

Van Tatenhove $(2011,2013)$ describes the process of increasing rule acceptance through participatory measures as "input-legitimacy," whereas "output-legitimacy" refers to whether decision-making succeeds in promoting common welfare for all people affected by these decisions. In SI the perceived misuse of money on behalf of the leadership and people involved in the management of the managed area led to perceptions of unequal benefits, lowering output-legitimacy. The experience of procedural unfairness through such unfair decision-making and/or outcomes thereof can erode "feelings of shared group membership with the authority concerned" as well as the identification with the rules that this authority establishes (Jackson et al., 2012, p. 1053). The previously-quoted statement by a fisherwoman in SI shows that this was the case, as she expressed that she perceived fishing inside the managed area no longer as poaching, but as a way to show her disagreement with the rules and with the unfair behavior of leadership.

Generally, trust and cooperation among resource users are proven to be crucial for effective local governance of commonpool resources (CPRs) and make a sustainable use of CPRs more likely (McCay and Acheson, 1987; Gibson et al., 2000; Basurto et al., 2016). This elucidates why a decrease in trust, including toward leadership, and cooperative behavior within the community that followed from the schism, recently diminished compliance with the marine closure in SI. Intermarriages were adding to this because they can counteract feelings of shared group membership toward leadership and increase tenurial claims over fishing access. This intensifies fishing pressure and potential conflicts over (access to) resources. Also, people from outside of the community bring in their own tribal identity and traditions, which are very diverse across Solomon Islands (Aswani, 2002). Finally, an increasing number of people (temporarily) migrate out of the communities for marriage or employment, but they uphold their customary rights. This can result in increased non-awareness of "outside rights holders" with regards to local rules and management arrangements. All together, these factors might imply less respect for the local customary leaders and the decisions made by them. Although the schism and intermarriages revealed in SI can be seen as rather case specific phenomena, they also demonstrate the high degree of stratification and contestation of socio-political and tenurial systems in Solomon Islands (Aswani, 1999). Furthermore, the case demonstrates the dynamic and dual role that the church can play in local marine management, as pointed out before.

In both case studies villagers perceived the marine closures as being more focused toward achieving conservation objectives, instead of serving primarily cultural and social purposes like former customary closures used to (Cinner and Aswani, 2007; Foale et al., 2011). Management had shifted from periodic closures to periodic openings/permanent closures, which limits the flexibility of these marine tenure systems (Hviding, 1998). Both management sites had been partly supported by and/or implemented in collaboration with external partners. They exemplify the hybrid approach that lays the basis for much of the current CBMRM practice that merges customary management and traditional ideas with conservation practice and sustainability discourses. Yet, locals distinguished between these practices and the underlying objectives, as other studies have found, too (Jupiter et al., 2014; Cohen and Steenbergen, 2015). Our study shows that this is likely to affect perceptions of legitimacy of these rule systems and thus local compliance with CBMRM. Also, violations of rules that were externally influenced were considered less severe than a breach of customary norms and taboos. These aspects should be considered by partner agencies that work with communities in the frame of CBMRM initiatives.

Market access and the lack of alternative livelihoods were increasing non-compliance in both case studies. Numerous studies have highlighted market access and proximity, and the commercialization of marine resources, as key drivers for resource (over-) exploitation, with the potential to affect local management regimes (Aswani, 2002; Cinner and McClanahan, 2006; Brewer et al., 2009; Cinner et al., 2012, 2016). Similarly, the reliance on fishing as single livelihood has been proven to negatively affect local compliance with marine conservation areas (Arias et al., 2015). On the other hand, evidence also suggests that high dependence on marine resources at the community level can be a contributing factor for sustainable local marine resource management (Cinner et al., 2016). The apparent contradiction may be explained by the potentially contrasting effects of dependence on marine resources at the household and the community level. While communities with a high overall reliance on marine resources can be compelled into collective action by this dependency (Ostrom, 2009), individual households within a community might be more strongly compelled to break 
the rules if marine resources constitute their sole option to generate income and sustenance.

The location and size of the managed areas restricted access to the most accessible (and productive) fishing grounds in front of the villages. In both cases location and size were decided based upon indigenous ecological knowledge. The locations of the closures were also selected due to their proximity to the villages and so to enhance feasibility of monitoring. Yet, because the managed areas constrained villagers in their ability to fish, this proximity partly turned into an additional driver for non-compliant behavior in both case studies. This illustrates how a feature that was initially seen as an advantage can turn into disadvantage when conditions and context change. Furthermore, it shows that there can be critical trade-offs between achieving ecological objectives and social acceptance (compliance) with regards to managed areas. Ecological requirements for conservation might require a certain spatial and geographical scale for management, which might not in all contexts be socially acceptable (Johannes, 2002; Foale and Manele, 2004; Mills et al., 2010), and hence less complied with. Besides, it points to the fact that the costs and benefits of conservation efforts might be unevenly affecting different social groups (see Eder, 2005 for a case study from Philippines). In SI especially older people and women were constrained by the managed area. In FJ particularly young fishermen who needed to fish because they were lacking an alternative income, but who at the same time did not have a boat to reach more distant fishing grounds, were bearing a higher burden. In this light the importance of continuous participative and communicative measures in order to increase ownership, legitimacy and support of management rules (Jentoft, 2000; Pomeroy et al., 2015) becomes even more evident. Such measures should take into account differentiated impacts of management efforts on diverse social groups (Gurney et al., 2015) and potentially adapt marine management to ensure more equitable arrangements.

At the same time, the just-mentioned reasons for noncompliant behavior again highlight the importance of acknowledging the wider social and economic context of illegal fishing practices and non-compliance. For examples from Indonesia, where existing local elites and complex patronage (patron-client) networks have contributed to non-compliance with marine management rules, and thus hampered conservation efforts, see Lowe (2002), Ferse et al. (2012), and Kusumawati and Visser (2016).

\section{Addressing Barriers to Monitoring and Enforcement}

Customary governance systems are not static over time but have always operated within dynamic socio-cultural, political and economic contexts (Aswani and Ruddle, 2013). This has similarly affected legal and institutional aspects of monitoring and enforcement, such as penalty systems. Also, as the Solomon Islands case study demonstrates, some institutions that strengthened customary tenure systems in a certain setting can have a different effect when the context changes.

At the same time, findings from FJ and SI reveal that diverse socio-cultural constraints can limit local monitoring and enforcement efforts, especially in a setting where sociocultural relationships between tribes, clans and families are highly complex and an important social capital, as well as a crucial aspect of local culture and identity. This shows how socio-cultural values that remain from customary systems and traditions can also potentially hinder the effective implementation of hybrid management arrangements if enforcement responsibilities solely rely on the local level.

Customary fishing rights, which are recognized by national law as part of customary law, are at the core of the local marine resource management schemes studied here. Yet, the local management arrangements (marine closures) as such were not legally recognized by any national law. This has created a legal pluralist situation where different legal ideas and systems exist within a single setting (Scaglion, 2004; Hinz, 2008; Jentoft et al., 2009). It is crucial to evaluate how customary and state law interact or to which extent one of them is dominant (Jentoft, 2011). Generally, customary institutions and law remain the core means to resolve disputes in rural communities in Pacific societies until now (NZLC, 2006), including in the context of marine resources. Hence, they play a key role for the enforcement of marine tenure systems. In the past, customary penalties for breaking taboos included beatings, banishment or destruction of property. Breaching marine customary taboos, such as marine closures, was mainly punished by compensation payments in form of traditional money or livestock, social alienation or exclusion (Cinner and Aswani, 2007; Jupiter et al., 2010). Yet, the national legal systems have largely constrained the customary penalty systems given that nowadays most customary penalties are prohibited under national law. This effectively made the customary approaches less powerful.

In the cases studied here, customary law was locally decisive for managing the use of and access to marine resources. Nevertheless, in the current settings the customary systems alone were no longer capable of enforcing these local rules and to sanction non-compliance. This was partly due to national laws that restricted the customary penalty systems, without (yet) providing an adequate substitute. This does not only show how modern legal systems can potentially lead to a (partial) erosion of customary management (Cinner and Aswani, 2007). It also highlights the need to clearly define and establish the roles and responsibilities of other (including government) actors involved in current CBMRM practice in order to ease their implementation and effective enforcement. In FJ and SI, sanctions that were practiced in cases of local non-compliance, such as oral warnings and public announcements, were showing limited success. Furthermore, those in charge of supervising compliance with local rules can be challenged by conflicting allegiances in pursuing their tasks, as is exemplified by the fish wardens in FJ. A similar situation was observed in an East African setting by de la Torre-Castro (2006), who cautioned that the local context, in particular the cultural setting, kinship and alliances, need to be carefully considered in the design of co-management institutions.

Previous studies have noticed similar shortcomings of local enforcement in local marine resource management in the 
South Pacific, while also highlighting financial and technical constraints for local monitoring (Minter, 2008; Jupiter et al., 2010; Pomeroy et al., 2015). These studies have called for communicative measures, such as awareness programs and conflict resolution exercises, as well as improved administration under the fisheries legislation and increased law enforcement. The latter aspect might imply registering local management plans and penalty systems under national legislation. The new Fisheries Management Act of Solomon Islands (enacted in 2015, implementation is underway) offers communities the right to do so. It shall thus help to make local rules and penalties legally enforceable. This could contribute to restrengthening local enforcement capabilities while involving government actors more directly in enforcement efforts, too. Yet, the limited financial, personnel and time resources of the government to exercise these responsibilities and therewith reach out to the local level should be kept in mind. Also, such "legalization" should account for the flexibility of marine tenure systems in their continuously evolving forms and allow for adaptive management (Hviding, 1998).

Although voluntary compliance is preferred and likely to increase through participatory and communicative measures that enhance legitimacy (Jentoft, 2000), a certain degree of enforcement is often necessary (Arias, 2015) to create or increase the deterrent threat for rule-breaking. Effective sanction mechanisms are also crucial to avoid "contingent compliance," because individuals base their decision (not) to follow rules on the (perceived) compliance of others, too (Pomeroy et al., 2015), as our study shows as well.

Furthermore, the importance of having graduated sanctions for successful CPR management has been highlighted (Ostrom, 1990). Graduated sanctions are flexible to the seriousness and context of the offense (increasing with the frequency and severity of the infringement) and might hence be perceived as more legitimate. The existence of graduated sanctions has been positively related to resource users' compliance behavior (Cinner et al., 2012). However, in both case studies, graduated sanctions were not provided for in the current setting. Generally, sanctions could include social sanctions-which have been proven successful in inducing community cooperation and compliance (Ostrom, 1990). The design and perceived fairness of the enforcement system are again likely to influence perceptions of legitimacy (Pomeroy et al., 2015). Sanction mechanisms should thus also be formulated in a participatory manner, e.g., through consultations on which sanctions could be locally feasible and desirable.

\section{CONCLUDING REMARKS}

Our study reveals multiple drivers for local non-compliance with local marine resource management in two case studies in the South Pacific. In other words, this article outlines that locals fished inside the marine closures studied here for a number of different reasons and exposes how these reasons were influenced by dynamic social, political and economic contexts.
Perceived legitimacy of decision-making and decision-makers was considerably influencing compliance behavior in our case studies. To address this driver of local (non-) compliance, broad participatory, transparent and communicative efforts are crucial (see also Ferse et al., 2010). These should involve women and youth-both groups are often less involved in local decisionmaking. Incentives to break rules due to market access and/or lack of alternative livelihoods can be difficult to tackle as they mostly lie beyond the local reach. Yet, it becomes clear that the governance system needs to react when such external factors change. This might imply the development of new rules.

Our results show that multiple drivers of (non-) compliance interact. Hence, when legitimacy of local management rules and leadership is high/increased, it may more readily outweigh other incentives for rule-breaking. Vice versa, when the strength of local leadership is decreasing this might negatively affect compliance dynamics. Our study highlights that drivers of (non-) compliance are highly contextual. They react to and depend on the broader dynamics of marine governance systems. In other words, if the context of the governance system changes, this can affect rule compliance decisively. We therefore argue that it is important to build fallback mechanisms into governance arrangements that allow for adaptive management of marine resources.

By showing that perceptions essentially shape people's compliance behavior, our study brings to attention the importance of assessing local perceptions of local rules, objectives and outcomes of resource management processes, as well as of people and actors involved in management. This also underlines the importance of qualitative research in the context of marine resource management (see also Barclay et al., 2017). In sum, while the scope of this research with its focus on two case studies appears limited, our study reveals under what pressures and circumstances compliance can decrease or increase. This understanding can inform future design and implementation of adaptive CBMRM and thus suggests applicability of the findings to the broader context of CBMRM in the region and beyond.

\section{AUTHOR CONTRIBUTIONS}

JR conducted the field research and data analysis and wrote the initial manuscript. All authors contributed substantially to revisions by providing theoretical, analytical, and empirical input.

\section{ACKNOWLEDGMENTS}

We sincerely thank all people who participated in this study as well as the local field assistants and interpreters who helped to facilitate research on the ground. We further wish to express our thanks to diverse stakeholders, including the Governments of Fiji and Solomon Islands, as well as community leaders, for their kind and productive collaboration. It helped immensely in facilitating this research project in both countries and in securing research permits. This work is part of the REPICORE project (grant 01LN1303A), funded by the German Ministry for Research and Education (BMBF) in the frame of the "Research 
for Sustainable Development Framework Program" (FONA), and contributes to the ICSU and UNESCO-sponsored "Program on Ecosystem Change and Society" (PECS). Finally, we thank the two reviewers for their insightful comments on a previous draft of this manuscript.

\section{REFERENCES}

Arias, A. (2015). Understanding and managing compliance in the nature conservation context. J. Environ. Manage. 153, 134-143. doi: 10.1016/j.jenvman.2015.02.013

Arias, A., Cinner, J. E., Jones, R. E., and Pressey, R. L. (2015). Levels and drivers of fishers' compliance with marine protected areas. Ecol. Soc. 20:19. doi: 10.5751/ES-07999-200419

Arias, A., and Sutton, S. G. (2013). Understanding recreational Fishers' compliance with no-take zones in the great barrier reef marine park. Ecol. Soc. 18:18. doi: 10.5751/ES-05872-180418

Aswani, S. (1997). Troubled water in South-western New Georgia, Solomon Islands: is codification of the commons a viable avenue for resource use regularisation? SPC Tradit. Mar. Resour. Manage. Knowl. Inform. Bull. 8, 2-16.

Aswani, S. (1999). Common property models of sea tenure: a case study from the Roviana and Vonavona Lagoons, New Georgia, Solomon Islands. Hum. Ecol. 27, 417-453. doi: 10.1023/A:1018727607651

Aswani, S. (2002). Assessing the effects of changing demographic and consumption patterns on sea tenure regimes in the Roviana Lagoon, Solomon Islands. Ambio 31, 272-284. doi: 10.1579/0044-7447-31.4.272

Aswani, S., Albert, S., Sabetian, A., and Furusawa, T. (2007). Customary management as precautionary and adaptive principles for protecting coral reefs in Oceania. Coral Reefs 26, 1009-1021. doi: 10.1007/s00338-007-0277-z

Aswani, S., and Ruddle, K. (2013). Design of realistic hybrid marine resource management programs. Pac. Sci. 67, 461-476. doi: 10.2984/67.3.11

Barclay, K., Voyer, M., Mazur, N., Payne, A. M., Mauli, S., Kinch, J., et al. (2017). The importance of qualitative social research for effective fisheries management. Fish. Res. 186, 426-438. doi: 10.1016/j.fishres.2016.08.007

Basurto, X., Blanco, E., Nenadovic, M., and Vollan, B. (2016). Integrating simultaneous pro-social and anti-social behaviour into theories of collective action. Sci. Adv. 2, 1-22. doi: 10.1126/sciadv. 1501220

Berkowitz, A. (2005). "An overview of the social norms approach," in Changing the Culture of College Drinking: A Socially Situated Health Communication Campaign, eds L. C. Lederman and L. P. Stewart (Cresskill, NJ: Hampton Press), 193-214.

Brewer, T. D., Cinner, J. E., Green, A., and Pandolfi, J. M. (2009). Thresholds and multiple scale interaction of environment, resource use, and market proximity on reef fishery resources in the Solomon Islands. Biol. Conserv. 142, 1797-1807. doi: 10.1016/j.biocon.2009.03.021

Caillaud, A., Boengkih, S., Evans-Illidge, E. A., Genolagani, J., Havemann, P., Henao, D., et al. (2004). Tabus or not taboos? How to use traditional environmental knowledge to support sustainable development of marine resources in Melanesia. SPC Traadit. Mar. Resour. Manage. Knowl. Inform. Bull. $17,14-36$.

Campbell, S. J., Hoey, A. S., Maynard, J., Kartawijaya, T., Cinner, J., Graham, N. A. J., et al. (2012). Weak compliance undermines the success of no-take zones in a large government-controlled marine protected area. PLOS ONE 7:e50074. doi: 10.1371/journal.pone.0050074

Cinner, J. E., McClanahan, T. R., MacNeil, M. A., Graham, N. A., Daw, T. M., Mukminin, A., et al. (2012). Comanagement of coral reef social-ecological systems. Proc. Natl. Acad. Sci. U.S.A. 109, 5219-5222. doi: $10.1073 /$ pnas.1121215109

Cinner, J. E., Huchery, C., MacNeil, M. A., Graham, N. A., McClanahan, T. R., Maina, J., et al. (2016). Bright spots among the world's coral reefs. Nature 535, 416-419. doi: 10.1038/nature 18607

Cinner, J. E., and Aswani, S. (2007). Integrating customary management into marine conservation. Biol. Conserv. 140, 201-216. doi: 10.1016/j.biocon.2007. 08.008

\section{SUPPLEMENTARY MATERIAL}

The Supplementary Material for this article can be found online at: http://journal.frontiersin.org/article/10.3389/fmars. 2017.00172/full\#supplementary-material

Cinner, J. E., and McClanahan, T. R. (2006). Socioeconomic factors that lead to overfishing in small-scale coral reef fisheries of Papua New Guinea. Environ. Conserv. 33, 73-80. doi: 10.1017/S0376892906002748

Cohen, P. J., and Steenbergen, D. J. (2015). Social dimensions of local fisheries co-management in the Coral Triangle. Environ. Conserv. 42, 1-11. doi: $10.1017 /$ S0376892914000423

Corbin, J., and Strauss, A. (2008). Basics of Qualitative Research: Techniques and Procedures for Developing Grounded Theory, 3rd Edn. London: Sage.

de la Torre-Castro, M. (2006). Beyond regulations in fisheries management: the dilemmas of the "beach recorders" Bwana Dikos in Zanzibar, Tanzania. Ecol. Soc. 11:35. doi: 10.5751/ES-01876-110235

Deutsche Forschungsgemeinschaft (DFG) (2013). Sicherung Guter Wissenschaftlicher Praxis: Empfehlungen der Kommission "Selbstkontrolle in der Wissenschaft." Weinheim: Wiley-VCH Verlag GmbH \& Co. KGaA. doi: 10.1002/9783527679188

De Vos, B. I., and Van Tatenhove, J. P. M. (2011). Trust relationships between fishers and government: new challenges for the co-management arrangements in the Dutch flatfish industry. Mar. Policy 35, 218-225. doi: 10.1016/j.marpol.2010.10.002

Eder, J. F. (2005). Coastal resource management and social differences in Philippine fishing communities. Hum. Ecol. 33, 147-169. doi: 10.1007/s10745-005-2430-Z

Ferse, S. C. A., Knittweis, L., Krause, G., Maddusila, A., and Glaser, M. (2012). Livelihoods of ornamental coral fishermen in South Sulawesi/Indonesia: implications for management. Coast. Manage. 40, 525-555. doi: 10.1080/08920753.2012.694801

Ferse, S. C. A., Manez Costa, M., Schwerdtner Manez, K., Adhuri, D. S., and Glaser, M. (2010). Allies, not aliens: increasing the role of local communities in marine protected area implementation. Environ. Conserv. 37, 23-34. doi: $10.1017 /$ S0376892910000172

Foale, S., Cohen, P., Januchowski-Hartley, S., Wenger, A., and Macintyre, M. (2011). Tenure and taboos: origins and implications for fisheries in the Pacific. Fish Fish. 12, 357-369. doi: 10.1111/j.1467-2979.2010.00395.x

Foale, S., and Manele, B. (2004). Social and political barriers to the use of Marine Protected Areas for conservation and fishery management in Melanesia. Asia Pac. Viewp. 45, 373-386. doi: 10.1111/j.1467-8373.2004.00247.x

Gezelius, S. S. (2002). Do norms count? state regulation and compliance in a Norwegian fishing community. Acta. Sociol. 45, 305-314.

Gezelius, S. S. (2003). Regulation and Compliance in the Atlantic Fisheries: State/Society Relations in the Management of Natural Resources. Dordrecht: Kluwer Academic Publishers.

Gezelius, S. S. (2004). Food, money, and morals: Compliance among natural resource harvesters. Hum. Ecol. 32, 615-634. doi: 10.1007/s10745-004-6099-5

Gibson, C., McKean, M., and Ostrom, E. (eds.). (2000). People and Forests: Communities, Institutions, and Governance. Cambridge, MA: MIT Press.

Govan, H., Tawake, A., Tabunakawai, K., Jenkins, A., Lasgorceix, A., Schwarz, A. M., et al. (2009). Status and Potential of Locally-managed Marine Areas in the South Pacific: Meeting Nature Conservation and Sustainable Livelihood Targets Through Wide-spread Implementation of LMMAs. Apia, Samoa.

Govan, H. (2013). Strategic review of inshore fisheries policies and strategies in Melanesia: Fiji, New Caledonia, Papua New Guinea, Solomon Islands, and Vanuatu. Part I: General Overview. Report to the Secretariat of the Pacific Community for the Melanesian Spearhead Group, Noumea, New Caledonia, 33

Gurney, G. G., Pressey, R. L., Cinner, J. E., Pollnac, R., and Campbell, S. J. (2015). Integrated conservation and development: evaluating a communitybased marine protected area project for equality of socioeconomic impacts. Philos. Trans. R. Soc. Lond. B Biol. Sci. 370:20140277. doi: 10.1098/rstb.2014. 0277 
Hatcher, A., Jaffry, S., Thebaud, O., and Bennett, E. (2000). Normative and social influences affecting compliance with fishery regulations normative and social influences affecting compliance with fishery regulations. Land Econ. 76, 448-461. doi: 10.2307/3147040

Hauck, M. (2008). Rethinking small-scale fisheries compliance. Mar. Policy 32, 635-642. doi: 10.1016/j.marpol.2007.11.004

Hinz, M. (2008). "Traditional governance and african customary law: comparative observations from a Namibian perspective," in Human Rights and the Rule of Law in Namibia, eds N. Horn and A. Bösl (Windhoek: MacMillan Namibia), 59-87.

Hønneland, G. (1999). A model of compliance in fisheries: theoretical foundations and practical application. Ocean Coast. Manag. 42, 699-716. doi: 10.1016/S0964-5691(99)00041-1

Hviding, E. (1998). Contextual flexibility: Present status and future of customary marine tenure in Solomon Islands. Ocean Coast. Manage. 40, 253-269. doi: 10.1016/S0964-5691(98)00042-8

Jackson, J., Bradford, B., Hough, M., Myhill, A., Quinton, P., and Tyler, T. R. (2012). Why do people comply with the law? Legitimacy and the influence of legal institutions. Br. J. Criminol. 52, 1051-1071. doi: 10.1093/bjc/azs032

Jentoft, S. (2000). Legitimacy and disappointment in fisheries management. Mar. Policy 24, 141-148. doi: 10.1016/S0308-597X(99)00025-1

Jentoft, S. (2011). Legal pluralism and the governability of fisheries and coastal systems. J. Legal Pluralism Unofficial Law 43, 149-172. doi: 10.1080/07329113. 2011.10756673

Jentoft, S., Bavinck, M., Johnson, D. S., and Thomson, K. T. (2009). Fisheries co-management and legal pluralism: how an analytical problem becomes an institutional one. Hum. Organ. 68, 27-38. doi: 10.17730/humo.68.1.h87q04 $245 \mathrm{t} 63094 \mathrm{r}$

Johannes, R. E. (1978). Traditional marine conservation methods in Oceania and their demise. Annu. Rev. Ecol. Syst. 9, 349-364. doi: 10.1146/annurev.es.09. 110178.002025

Johannes, R. E. (2002). The renaissance of community-based marine resource management in Oceania. Annu. Rev. Ecol. Syst. 33, 317-340. doi: 10.1146/ annurev.ecolsys.33.010802.150524

Jupiter, S. D., Clarke, P., Prasad, S. R., Egli, D. P., Tui, T., Caginitoba, A., et al. (2010). Non-compliance Compliance with Management Rules and Its Implications for Traditional Inshore Fisheries in Fiji. Wildlife Conservation Society-Fiji Technical Report no. 04/10 (Suva), 29.

Jupiter, S. D., Cohen, P. J., Weeks, R., Tawake, A., and Govan, H. (2014). Locallymanaged marine areas: multiple objectives and diverse strategies. Pacific Conserv. Biol. 20, 165-179. doi: 10.1071/PC140165

Keane, A., Jones, J. P. G., Edwards-Jones, G., and Milner-Gulland, E. J. (2008). The sleeping policeman: understanding issues of enforcement and compliance in conservation. Anim. Conserv. 11, 75-82. doi: 10.1111/j.1469-1795.2008.00170.x

Kuperan, K., and Sutinen, J. G. (1998). Blue water crime: deterrence, legitimacy, and compliance in fisheries. Law Soc. Rev. 32, 309-338. doi: 10.2307/827765

Kusumawati, R., and Visser, L. (2016). Capturing the elite in marine conservation in Northeast Kalimantan. Hum. Ecol. 44, 301-310. doi: 10.1007/s10745-0169830-0

Lowe, C. (2002). Who is to blame? Logics of responsibility in the live reef food fish trade in Sulawesi, Indonesia. SPC Live Reef Fish Inf. Bull. 10, 7-16.

Madrigal-Ballestero, R., Schlüter, A., and Claudia Lopez, M. (2013). What makes them follow the rules? Empirical evidence from turtle egg harvesters in Costa Rica. Mar. Policy 37, 270-277. doi: 10.1016/j.marpol.2012.05.009

Mancini Billson, J. (2006). “Conducting focus group research across cultures: consistency and comparability. ESRC Research Group on Wellbeing in Developing Countries," in Working Paper, 27.

McCay, B., and Acheson, J., (eds.). (1987). "Human ecology of the commons," in The Question of the Commons: The Culture and Ecology of Communal Resources (Tucson: The University of Arizona Press), 143-167.

Mills, M., Pressey, R. L., Weeks, R., Foale, S., and Ban, N. C. (2010). A mismatch of scales: challenges in planning for implementation of marine protected areas in the Coral Triangle. Conserv. Lett. 3, 291-303. doi: 10.1111/j.1755-263X.2010. 00134.x

Minter, A. (2008). Compliance and Enforcement for Coastal Fisheries Management in Fiji. Suva: IUCN Regional Office for Oceania.

NZLC (2006). "Converging currents: Custom and human rights in the Pacific," in Study Paper 17 (Wellington: New Zealand Law Commission), 312.

Ostrom, E. (1990). Governing the Commons: The Evolution of Institutions for Collective Action. New York, NY: Cambridge University Press.

Ostrom, E. (2007). A diagnostic approach for going beyond panaceas. Proc. Natl. Acad. Sci. U.S.A. 104, 15181-15187. doi: 10.1073/pnas.0702288104

Ostrom, E. (2009). A general framework for analyzing sustainability of social-ecological systems. Science 325, 419-422. doi: 10.1126/science. 1172133

Pollnac, R., Christie, P., Cinner, J. E., Dalton, T., Daw, T. M., Forrester, G. E., et al. (2010). Marine reserves as linked social-ecological systems. Proc. Natl. Acad. Sci. U.S.A. 107, 43-46. doi: 10.1073/pnas.0908266107

Pomeroy, R., Parks, J., Reaugh-Flower, K., Guidote, M., Govan, H., and Atkinson, S. (2015). Status and priority capacity needs for local compliance and community-supported enforcement of marine resource rules and regulations in the coral triangle region. Coast. Manage. 43, 301-328. doi: 10.1080/08920753.2015.1030330

Raakjaer Nielsen, J. (2003). An analytical framework for studying: compliance and legitimacy in fisheries management. Mar. Policy 27, 425-432. doi: 10.1016/S0308-597X(03)00022-8

Scaglion, R. (2004). "Legal pluralism in Pacific Island societies," in Globalization and Culture Change in the Pacific Islands, ed V. Lockwood (Upper Saddle River, NJ: Pearson/Prentice Hall), 86-101.

Schlüter, A., and Madrigal, R. (2012). The SES framework in a marine setting: methodological lessons. Ration. Mark. Morals 3, 148-167.

Schlüter, A., and Theesfeld, I. (2010). The grammar of institutions: the challenge of distinguishing between strategies, norms, and rules. Ration. Soc. 22, 445-475. doi: $10.1177 / 1043463110377299$

Silverman, D. (2010). Doing Qualitative Research - A Practical Handbook, 3rd Edn. London: Sage.

Sutinen, J. G., and Andersen, P. (1985). The economics of fisheries law enforcement. Land Econ. 61, 387-397. doi: 10.2307/3146156

Sutinen, J. G., and Kuperan, K. (1999). A socio-economic theory of regulatory compliance. Int. J. Soc. Econ. 26, 174-193. doi: 10.1108/03068299910229569

Tyler, T. R. (2006). Psychological perspectives on legitimacy and legitimation. Annu. Rev. Psychol. 57, 375-400. doi: 10.1146/annurev.psych.57.102904. 190038

Van Tatenhove, J. P. M. (2011). Integrated marine governance: questions of legitimacy. MAST 10, 87-113.

Van Tatenhove, J. P. M. (2013). How to turn the tide: developing legitimate marine governance arrangements at the level of the regional seas. Ocean Coast. Manag. 71, 296-304. doi: 10.1016/j.ocecoaman.2012.11.004

Veitayaki, J. (1998). Traditional and community-based marine resources management system in Fiji: an evolving integrated process. Coast. Manage. 26, 47-60. doi: 10.1080/08920759809362342

Weeks, R., and Jupiter, S. D. (2013). Adaptive comanagement of a marine protected area network in Fiji. Conserv. Biol. 27, 1234-1244. doi: 10.1111/cobi.12153

Conflict of Interest Statement: The authors declare that the research was conducted in the absence of any commercial or financial relationships that could be construed as a potential conflict of interest.

Copyright (C) 2017 Rohe, Aswani, Schlüter and Ferse. This is an open-access article distributed under the terms of the Creative Commons Attribution License (CC BY). The use, distribution or reproduction in other forums is permitted, provided the original author(s) or licensor are credited and that the original publication in this journal is cited, in accordance with accepted academic practice. No use, distribution or reproduction is permitted which does not comply with these terms. 